\title{
Being bullied during childhood and the risk of obesity in adulthood: A co-twin control study
}

\author{
M. Vámosi ${ }^{1^{*}}$, B. L. Heitmann ${ }^{2}$, M. Thinggaard ${ }^{3}$, K. O. Kyvik ${ }^{3,4,5}$ \\ ${ }^{1}$ Unit of Nursing research, Department of Public Health, Aarhus University, Aarhus, Denmark; \\ *Corresponding Author: Marianne.Vamosi@sygeplejevid.au.dk \\ ${ }^{2}$ Research Unit for Dietary Studies, Institute of Preventive Medicine Copenhagen University Hospitals, Frederiksberg Hospital, Fre- \\ deriksberg, Denmark \\ ${ }^{3}$ The Danish Twin Registry, Epidemiology, University of Southern Denmark, Odense, Denmark \\ ${ }^{4}$ Institute of Regional Health Services Research, University of Southern Denmark, Odense, Denmark \\ ${ }^{5}$ Odense Patient Data Explorative Network (OPEN), Odense University Hospital, Odense, Denmark
}

Received 1 November 2012; revised 2 December 2012; accepted 13 December 2012

\section{ABSTRACT}

Background: The etiology of adult obesity is still poorly understood. It has been shown that overweight children suffer from adverse psychological events, but less is known about the association of adverse psychological factors among normal weight children and adult obesity. Aim: The aim of this study was to examine being bullied during childhood could be associated with development of adult obesity. Methods: Adult, same-sexed twin pairs discordant for BMI were identified from the Danish Twin Registry. The twins underwent an interview and a physical examination. Data were analyzed by means of a growth-curve model and an intra-pair comparison. This design controls for other influences of early lifestyle and socio economic status and is therefore a powerful tool to study independent effects of specific exposures. Results: In total, $236(81.7 \%)$ of the twin individuals identified participated in the study. Participants who reported having been bullied in school, had attained a BMI which was on average $1.4 \mathrm{~kg} / \mathrm{m}^{2}(95 \% \mathrm{Cl}=$ $0.2 ; 2.5, p=0.02$ ) higher than those not bullied. Two other questions on specific types of bullying resulted in $\mathrm{BMI}$ that were $1.1 \mathrm{~kg} / \mathrm{m}^{2}(\mathrm{Cl}=0.1$; $2.2, \mathrm{p}=0.03)$ and $1.9 \mathrm{~kg} / \mathrm{m}^{2}(\mathrm{Cl}=0.7 ; 3.1, \mathrm{p}=$ 0.002 ) larger than subjects who had not been exposed to bullying. There was a direct association between intra pair differences in BMI and exposure to bullying. Conclusion: The results of the study could indicate that being bullied during childhood seems be associated with adult obesity.

Keywords: Overweight; Obesity; Childhood; Being
Bullied; Risk Factor; Twin Study; Psychological Determinants

\section{INTRODUCTION}

A number of previous studies have examined the influence of psychosocial factors in childhood and development of adult obesity [1-4]. Psychological factors identified included inadequate sleep, depressive symptoms, mood disorders and traumatic events during childhood, including abuse and parental neglect [5-7]. Recent studies propose that consequences of childhood exposure to bullying have been studied in relation to later psychosocial health and quality of life [6,8-10], and previous studies have examined the influence of bullying among children who were already overweight or obese in relation to different health outcomes, but to our knowledge it has not previously been examined whether childhood bullying could be related to the subsequent development of adult obesity among initially normal weight children [11].

The definition of being bullied is: "Bullying is when someone repeatedly and on purpose says or does mean or hurtful things to another person who has a hard time defending himself or herself" [8]. Bullying can take many forms including: Verbal bullying such as calling names and verbal harassment or isolation, e.g. leaving a person out of a group. Bullying can also be physical such as pushing, hitting, or kicking, telling lies and spreading false rumors. Taking money or other things from someone or damaging someone's personal property and threatening or forcing another person to do things they don't want to do. Finally racial, sexual bullying and cyber-bullying (via cell phone or the Internet) are other types of bullying [8].

Consequently, the aim of the present study was to examine whether victims of bullying in school developed more adult obesity than non-victims. 


\section{METHODS}

\subsection{Twin Studies as Research Method}

The classical twin study compares similarity between monozygotic (MZ) twins with that of dizygotic (DZ) twins and is used to study the relative importance of genetic and environmental factors on a phenotype $[12,13]$. Another type of twin study is the co-twin control study where influences of environmental factors are studied among twins discordant for a trait $[12,13]$, i.e. a matched case-control study. The strength of this type of study is the ability to control for socioeconomic factors, maternal and paternal age and environmental exposure in childhood. This type of design is thus more powerful to study independent effects than conventional case-control studies $[12,13]$. These studies may be based on MZ twins only, to account fully for genetic effects, but in our case we have included DZ twins also. The Danish Twin Registry (DTR) is the oldest population based twin register in the world and among the largest $[14,15]$. These twins have been found to be representative of the general population in Denmark with regard to many diseases and mortality $[16,17]$.

\subsection{The Twin Participants}

A questionnaire on health and health related behavior was sent by mail to 46,418 twin individuals who were aged 20 - 71 years in 2002. After one reminder, 34,944 individuals $(75.3 \%)$ had returned the questionnaire and from these data BMI was calculated based on self-reported height and weight.

\subsection{Inclusion Criteria}

The pairs discordant for BMI, i.e. one twin having a BMI $>30 \mathrm{~kg} / \mathrm{m}^{2}$ (obesity) and the other twin a BMI between 20 and $25 \mathrm{~kg} / \mathrm{m}^{2}$ (normal), were selected. Furthermore, twins in a pair should be of the same sex and their age in 2002 should not exceed 50 years. A total of 146 complete twin pairs fulfilled these criteria in 2006 . Three subjects could not be contacted resulting in 143 complete pairs and 3 single persons, i.e. 289 twin individuals. These subjects were invited to participate in a structured interview and a physical examination which took place in their home or in a nearby nursing school in 2006 [18]. All were interviewed without any relatives, including the co-twin, being present and by the same interviewer. The structured interview consisted of a total of 145 questions from validated questionnaires [8,19-25].

\subsection{Exclusion Criteria}

The twins who would report being overweight before starting school and those who did not answer the questions on bullying would be excluded from further analysis with their co-twins.

\subsection{The Bully Questionnaire}

The questionnaires dealt with various health related topics including mental and physical problems, the perception of stress, experiences of having been bullied in childhood, growth and height history, eating habits, perception of body shape and of parental care and neglect [8,19-25]. Having been a victim of bullying in school was assessed by means of the Olweus Bully/Victim Questionnaire (OBVQ) which has been used in a number of previous studies [26-28]. In 2006, a study demonstrated that the OBVQ instrument had satisfactory psychometric properties; including construct validity and reliability [28]. The OBVQ questionnaire comprises a total of 40 questions about social relations in school, including bullying and teasing [29]. We used the reduced version consisting of 13 questions (Table 1) since the twins had to recall their school experiences many years earlier [29].

For questions $1-11$ the answer options consisted of 5 categories: Question one offered possibilities for answering from "Very bad" to "Very well". Question two offered possibilities for answering from "No good friends" to "More than 5 good friends" and questions 3 - 11 offered possibilities for answering from: "No, I was not bullied" to "It happened several times a week". For those who remembered never having been bullied the questionnaire stopped with question three. Answer options for question 12 was "Yes" or "No", whereas for question 13 the possibilities were "No contact", "Contact once" and "Contact several times" [29].

Only few individuals gave answers in the extreme categories and therefore the answer categories I-II and III$\mathrm{V}$ were subsequently merged for question 1 , whereas answer categories I-III and IV-V were merged for question 2. For questions 3 - 10 answer categories II-V were merged, for question 11 answer categories I-II, and III-V and for question 13 answer categories II-III were merged.

The height and weight questionnaire was developed and used by the Finnish Twin Register and was used with permission from Professor Jaakko Kaprio.

The twin individuals were asked to report how their height and weight had developed during childhood compared to that of their co-twin and of peers.

The questions were covering the age groups: $0-6$ years (before school age as Danish children start school at the age of six), $7-12$ years, $13-16$ years, $17-19$ years, $20-23$ years, last year, and finally the past six months.

The answer possibilities for height of co-twin and peers were: higher, similar or lower than co-twin/peers, and for the weights lighter, similar, a little more over- 
Table 1. Descriptive statistics.

\begin{tabular}{|c|c|c|}
\hline & Males & Females \\
\hline No. $(\%)$ & $77(32.6)$ & $159(67.4)$ \\
\hline \multicolumn{3}{|l|}{ Zygosity [No.]: } \\
\hline MZ (complete pair) & $13(6)$ & $45(21)$ \\
\hline DZ (complete pair) & $64(30)$ & $106(48)$ \\
\hline Unknown (complete pair) & 0 & $8(4)$ \\
\hline Mean age in 2006 (year) (SD) & $40.4(8.4)$ & $41.4(7.3)$ \\
\hline Mean BMI (weight $/ \mathrm{m}^{2}$ ) in 2002 (SD) & $27.3(4.4)$ & $28.4(7.1)$ \\
\hline Mean BMI (weight $/ \mathrm{m}^{2}$ ) in 2006 (SD) & $28.8(4.8)$ & $29.5(6.8)$ \\
\hline \multicolumn{3}{|l|}{ BMI at ages 20,30 and $40\left(\right.$ weight $\left./ \mathrm{m}^{2}\right)$ : } \\
\hline Number of twin participants at age 20 & 76 & 155 \\
\hline Mean BMI at age 20 (SD) & $24.0(2.9)$ & $23.4(4.3)$ \\
\hline Number of twin participants at age 30 & 61 & 144 \\
\hline Mean BMI at age $30(\mathrm{SD})$ & $25.7(3.5)$ & $25.9(5.6)$ \\
\hline Number of twin participants at age 40 & 47 & 100 \\
\hline Mean BMI at age 40 (SD) & $26.9(4.0)$ & $27.0(6.0)$ \\
\hline \multicolumn{3}{|l|}{ The Questions about bullying [No. (\%)] } \\
\hline 1) When in school, how did you feel during school breaks? ${ }^{\dagger}$ & $18(23.4)$ & $64(40.3)$ \\
\hline 2) How many good friends did you have among your classmates? ?† $^{\dagger \dagger}$ & $33(42.9)$ & $124(78.0)$ \\
\hline 3) How often were you bullied in school? $?^{i \dagger \dagger}$ & $56(72.7)$ & $119(74.8)$ \\
\hline $\begin{array}{l}\text { 4) I was made a fool of, called nasty names and was teased in an } \\
\text { embarrassing and hurtful way. }{ }^{\dagger \dagger}\end{array}$ & $41(53.3)$ & $87(54.7)$ \\
\hline $\begin{array}{l}\text { 5) Schoolmates on purpose tried to shut me out, exclude me or } \\
\text { completely overlooked me. }{ }^{\dagger \dagger \dagger}\end{array}$ & $28(36.4)$ & $77(48.4)$ \\
\hline 6) I was hit, kicked, pushed or locked up, had my hair pulled. ${ }^{\dagger \dagger}$ & $22(28.6)$ & $42(26.4)$ \\
\hline $\begin{array}{l}\text { 7) Schoolmates spread lies or false rumors about me and tried to turn } \\
\text { the others against me. }{ }^{\dagger \dagger}\end{array}$ & $22(28.6)$ & $48(30.4)$ \\
\hline $\begin{array}{l}\text { 8) Money and other things have been stolen from me or have been } \\
\text { ruined. }{ }^{\dagger \dagger}\end{array}$ & $16(20.8)$ & $24(15.2)$ \\
\hline $\begin{array}{l}\text { 9) I have been threatened and forced to do things that I did not want } \\
\text { to do. }{ }^{f \dagger i}\end{array}$ & $8(10.4)$ & $22(13.9)$ \\
\hline $\begin{array}{l}\text { 10) I have been subject to nasty words or comments of a sexual nature } \\
\text { (on genitals or sexual orientation). }{ }^{\dagger \dagger}\end{array}$ & $8(10.4)$ & $21(13.3)$ \\
\hline 11) How long were you bullied?* & $34(44.2)$ & $80(50.6)$ \\
\hline 12) Did you tell anyone that you were bullied? If yes, then to whom? ?** $^{*}$ & $42(75.0)$ & $54(44.6)$ \\
\hline $\begin{array}{l}\text { 13) Did an adult in your home contact the school to try to stop the } \\
\text { bullying of you in school? }{ }^{* *}\end{array}$ & $47(94.0)$ & $89(83.2)$ \\
\hline
\end{tabular}

"Number in the category "bad"; "Number in the category "0 - 3 friends"; "i† Number in the category "yes"; *Number in the category "more than 1 month"; "Number in the category "no"; The questions about bullying have been translated from Danish by an authorized translator. 
weight or more overweight than the co-twin, or others at the same age.

\subsection{Measurements}

The twin individuals were also asked to remember their weights in $\mathrm{kg}$ at ages 18, 20, 25, 30, 35, 40, 45 and 50 years up to the present age.

Physical measurements of height and weight were taken with the participants wearing light indoor clothes and no shoes [30]. The same standard folding ruler and bathroom scale were used throughout the study. Height was measured in meters with two decimals and weight measured in kilograms with one decimal by the same investigator.

From the answers to the questions about weight at different ages during adulthood and the weight measured in 2006 we calculated BMI from the age of 20 and with 5 years of intervals up until present age, while using the same height measurement taken in 2006. Since height does not change much from the age of 20 until the midfifties, this was considered a valid method [30,31].

The study was approved by the Scientific-Ethical Committee of Vejle and Funen Counties (J nr VF- 20030155). Each participant was guaranteed anonymity with regard to publication and they were guaranteed that nothing being said in the interview would be disclosed to the cotwin.

\section{STATISTICAL ANALYSIS}

As the OBVQ questionnaire had no own scoring system which was recommended by Olweus, each question were analysed separately. The answers to all the questions were dichotomized into two groups (the "no" answer and "how often" answers were summarized) after testing for similarity with regard to BMI, because of the fairly small sample and to ensure the association with BMI to be similar in the groups. The analysis of the descriptive statistics included an intra-pair comparison and a growth curve model.

\subsection{Intra-Pair Twin Comparison}

This design utilized the complete twin pairs who participated $(n=109)$ only and not the singletons $(n=18)$. Twin pairs, who reported to having been discordant for weight already when starting school, were also excluded from further analysis.

In the intra-pair analysis we tested if the twin, who was bullied in school (considered to be the "case") had a higher probability of being the heaviest compared to the twin who was not bullied in school (considered to be the "control"). We also tested whether the probability increased with higher intra-pair differences in BMI.

\subsection{Growth-Curve Model}

The growth-curve model analyses the association between BMI from age 20 and the answers to the 13 questions about bullying using Wald test and a mixed-effects linear regression model. Each question was analyzed separately and adjustments were subsequently made for age and sex, allowing for a random intercept and a random slope.

By these procedures, unbiased standard errors, regression coefficients and p-values were derived [32]. A hierarchical model was also applied to test if the twin design had a significant influence on the growth in BMI.

The statistical analysis was carried out using Stata 9.2 (StataCorp, 2007). For the analysis of the intra-pair twin comparison the ptrend command in STATA was used. Finally the growth-curve model was analyzed by use of the xtmixed command, which allows for individuals having a random intercept and a random slope.

\section{RESULTS}

In total, 236 (109 complete and 18 broken twin pairs) out of the 289 twin individuals chose to participate in the study, i.e. the participation rate was $81.7 \%$. Due to the matched design we utilized the complete twin pairs only and not the singletons. The 236 participants, 77 males and 159 females and 58 were MZ, 170 DZ and 8 of unclassifiable zygosity.

The descriptive results can be seen in Table 1. The twins who reported being overweight before starting school $(n=47)$ and those who did not answer the questions on bullying $(n=2)$ were excluded from further analysis with their co-twins. In total, 100 twin pairs were used in the intra pair analysis. A large part of the obese participants $(74 \%)$ reported having been bullied during childhood. In four of the bully questions the male twin participants generally scored higher whereas in the remaining nine of the questions the female twin participants scored higher (Table 1).

Table 2 shows the association between intra-pair twin difference in BMI at the age of 20 and childhood bullying for all the 13 bully questions. The results are shown as the proportion of times that the co-twin who had the highest BMI was also the one who was exposed to bullying in childhood, with increase in intra-pair difference of BMI.

Three of the 13 bully questions: "I was hit, kicked etc." (Regression coefficient $(\mathrm{RC})=0.17, \mathrm{p}=0.04)$, "Schoolmates spread lies about me etc." $(\mathrm{RC}=0.16, \mathrm{p}=0.04)$ and "How long were you bullied" $(\mathrm{RC}=0.16, \mathrm{p}=0.05)$ were associated with adult obesity.

Figure 1 shows the associations between the three questions mentioned above and the intra pair difference in BMI. This figure shows the proportion of times that 
Table 2. Result of the intrapair analysis. The results are given as the increase in the proportion of times the co-twin, who had the highest BMI, also was the one who perceived having been bullyed during childhood, with increase in intra pair difference of BMI.

\begin{tabular}{|c|c|c|}
\hline Binary variables: The 13 bully questions & Regression coefficient & p-value \\
\hline 1) When in school, how did you feel during school breaks? ? $^{\dagger}$ & -0.075 & 0.38 \\
\hline 2) How many good friends did you... ${ }^{\dagger \dagger}$ & -0.125 & 0.10 \\
\hline 3) How often were you bullied in school? ${ }^{\dagger \dagger}$ & 0.007 & 0.94 \\
\hline 4) I was made a fool of, called nasty names and... ${ }^{\dagger \dagger}$ & 0.039 & 0.59 \\
\hline 5) Schoolmates on purpose tried to shut me out.... ${ }^{\dagger \dagger}$ & 0.050 & 0.49 \\
\hline 6) I was hit, kicked, pushed or locked up... ${ }^{\dagger \dagger}$ & 0.169 & 0.04 \\
\hline 7) Schoolmates spread lies or false rumors about... ${ }^{\dagger \dagger}$ & 0.156 & 0.04 \\
\hline 8) Money and other things have been stolen... & 0.056 & 0.55 \\
\hline 9) I have been threatened and forced to do things... ${ }^{i \dagger \dagger}$ & -0.067 & 0.46 \\
\hline 10) I have been subject to nasty words... ${ }^{\dagger \dagger}$ & -0.004 & 0.96 \\
\hline 11) How long were you bullied?* & 0.156 & 0.05 \\
\hline 12) Did you tell anyone that you were bullied? ${ }^{* *}$ & 0.016 & 0.87 \\
\hline $\begin{array}{l}\text { 13) Did an adult in your home contact the school to try to stop the } \\
\text { bullying of you in school? }{ }^{* *}\end{array}$ & 0.111 & 0.44 \\
\hline
\end{tabular}

the co-twin, who had the highest BMI, was also the one who was exposed to the specific bully victim question, based on the magnitude of the intra-pair difference in BMI. The three bully items all show a direct trend, which have a good fit for all three bully questions.

Table 3 shows the BMI growth-curve model regression coefficients for each of the 13 bully questions, after adjustment for age and gender.

Subjects who reported "Yes" to "How often were you bullied in school?" had attained a BMI which was on average $1.4 \mathrm{~kg} / \mathrm{m}^{2}$ larger $(\mathrm{RC}=1.4(0.2 ; 2.5), \mathrm{p}=0.02)$ than subjects who were not bullied. Those who answered "Yes" to "I was made a fool of" in childhood, had attained a BMI which was on average $1.1 \mathrm{~kg} / \mathrm{m}^{2}$ larger (RC $=1.1(0.1 ; 2.2), \mathrm{p}=0.03)$ than subjects who answered "No" to this. The participants who answered "Yes" to "Schoolmates spread lies about me" had attained a BMI which was on average $1.9 \mathrm{~kg} / \mathrm{m}^{2}$ larger $(\mathrm{RC}=1.9(0.7$; $3.1), p=0.002$ ) than subjects who had answered "No" to this question.

These analyses did not show any improvement of the BMI growth curve model when adjustments were made for the twin design.

The results are given as the increase in the proportion of times the co-twin, who had the highest BMI, also was the one who was exposed to have been bullied in childhood, with increase in intra pair difference of BMI.

\section{DISCUSSION}

This study has shown that being a victim of bullying during childhood is associated with obesity at age 20 . Because of the matching within twin pairs, these findings were independent of early lifestyle and childhood socioeconomic factors. Those who reported they had experienced being bullied in childhood had attained an adult BMI which was on average $1.4 \mathrm{~kg} / \mathrm{m}^{2}$ or approximately 4 $\mathrm{kg}$ higher than at those who did not report this.

We found that the associations attenuated to some degree between the ages of 20 and 41 years. From the age of about 20 years, young Danes move away from home and with regard to twins, also from each other. Here they start different types of education and subsequently careers. Women might also experience differences in parity.

This increasingly different environment may have contributed to a "thinning out" of the effect on adult obesity of having been bullied as a normal weight child.

The reason for using twin pairs discordant for both exposure and outcome in the analysis is that twins concordant for exposure do not contribute to the analysis. If they are exposed to bullying to the same degree this can not be the explanation for the difference in BMI.

The analyses did not show any improvement of the BMI growth curve model when adjustment was made for the twin design and it thus seems to be valid to do the 
Table 3. The results from the growth-curve models in relation to BMI at the ages $20-55$.

\begin{tabular}{|c|c|c|c|}
\hline $\begin{array}{l}\text { Binary variables: The } 13 \text { bully questions } \\
\text { adjusted for age and gender }\end{array}$ & $\mathrm{N}^{\ddagger}$ (unique twins) & $\begin{array}{l}\text { Regression } \\
\text { coefficient }\end{array}$ & p-value \\
\hline 1) When in school, how did you feel during school breaks? & $1256(187)$ & $0.4[-0.7 ; 1.6]$ & 0.47 \\
\hline 2) How many good friends did you... ${ }^{\dagger}$ & $1256(187)$ & $-0.4[-1.6 ; 0.7]$ & 0.46 \\
\hline 3) How often were you bullied in school? $?^{\dagger \dagger}$ & $1256(187)$ & $1.4[0.2 ; 2.5]$ & 0.02 \\
\hline 4) I was made a fool of, called nasty names and... ${ }^{. \dagger \dagger}$ & $1256(187)$ & $1.1[0.1 ; 2.2]$ & 0.03 \\
\hline 5) Schoolmates on purpose tried to shut me out.... ${ }^{\dagger \dagger}$ & $1256(187)$ & $0.9[-0.2 ; 1.9]$ & 0.12 \\
\hline 6) I was hit, kicked, pushed or locked up... ${ }^{\dagger \dagger}$ & $1256(187)$ & $0.8[-0.4 ; 2.1]$ & 0.19 \\
\hline 7) Schoolmates spread lies or false rumors about... ${ }^{\dagger \dagger}$ & $1256(187)$ & $1.9[0.7 ; 3.1]$ & 0.002 \\
\hline 8) Money and other things have been stolen... ${ }^{\dagger \dagger}$ & $1256(187)$ & $1.3[-0.1 ; 2.8]$ & 0.07 \\
\hline 9) I have been threatened and forced to do things... ${ }^{i \dagger \dagger}$ & $1256(187)$ & $-1.1[-2.8 ; 0.6]$ & 0.21 \\
\hline 10) I have been subject to nasty words... ${ }^{\dagger \dagger}$ & $1256(187)$ & $1.4[-0.2 ; 3.1]$ & 0.08 \\
\hline 11) How long were you bullied?* & $1251(186)$ & $0.9[-0.2 ; 2.0]$ & 0.09 \\
\hline 12) Did you tell anyone that you were bullied?* & $881(132)$ & $1,0[-0.4 ; 2.3]$ & 0.17 \\
\hline $\begin{array}{l}\text { 13) Did an adult in your home contact the school to try to stop } \\
\text { the bullying of you in school? }\end{array}$ & $793(118)$ & $-0.3[-2.4 ; 1.8]$ & 0.78 \\
\hline
\end{tabular}

${ }^{\dagger} \mathrm{N}$ symbolizes the number of BMI's given at different ages for the twins; ${ }^{\dagger}$ Reference category is "good"; ${ }^{\dagger \dagger}$ Reference category is "more than 3 friends"; ${ }^{\dagger \dagger}$ Reference category is "no"; "Reference category is " $0-1$ month"; * Reference category is "yes".

(6) I was hit, kicked...

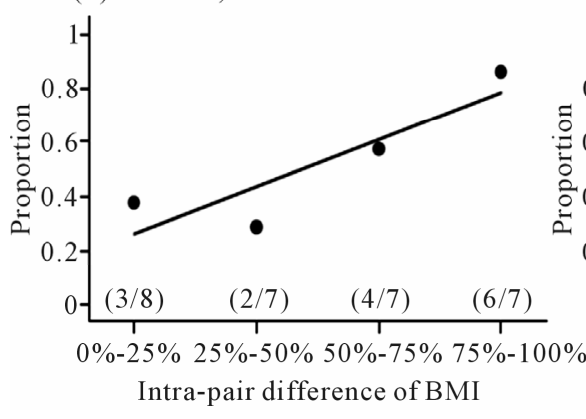

(7) Schoolmates spread lies...

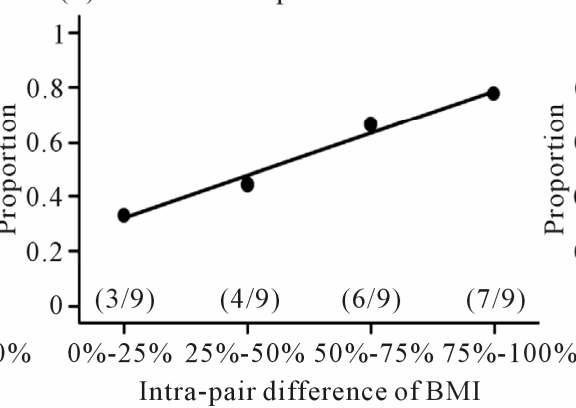

(11) How long were you bullied...

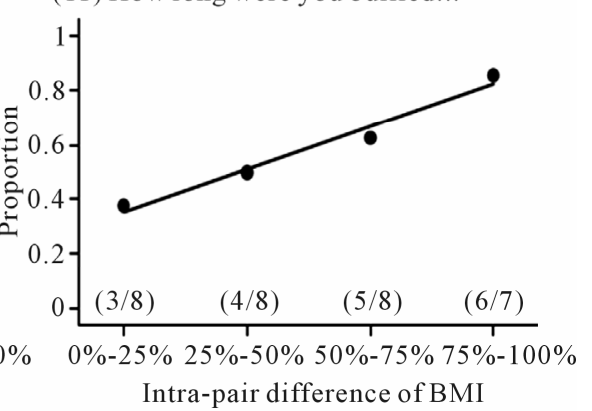

Figure 1. The trend of the proportions with increasing intra-pair comparison of BMI for 3 bully questions at the age of 20.

analysis using this model.

This study has a number of strengths. The participation rate was high $(81.7 \%)$ and the study population originated from an unselected population based twin survey, where the focus was not on obesity.

Twin pairs discordant for obesity are few, and the relatively big sample is an indication that the study base is actually unselected in this respect.

To ensure reliability of the data, the same investigator visited all the twins, who could choose between being visited at home or go to the nearest nursing college. The interviews took place with no relatives present, including the co-twin, which means that twin individuals had the opportunity to answer without being influenced by the opinion of their relatives. It is expected that this may have made it easier for the twins to answer potentially sensitive questions and thus it increases the validity of the answers. In order to minimize misclassification, the same ruler and scale were used for all twins, and all measurements were done twice.

We have no reason to believe that the associations found in the study should differ between twins and singletons, as studies have shown that twins are representative of the general population for most traits and diseases, e.g. type 2 diabetes, obesity, cardiovascular diseases and mortality [21,33].

We furthermore analyzed MZ and DZ twins separately and generally found similar results but due to power problems we chose not to split the sample into two.

There were also some limitations to this study. The information on weight and height were self-reported in the 2002 questionnaire and this may be considered a limita- 
tion, as subjects may underestimate their weight and overestimate their height, which could underestimate BMI.

A number of studies do find that self-reports of weight and height correlate well with measurements, though [34, 35].

We found more females than males among the discordant pairs. This might relate to for example differences in parity, as this is a well known determinant of weight gain, also post-partum.

Having had more men in the sample might have changed the results somewhat, since men and women have different patterns of bullying behavior and experience, i.e. males are more exposed to physical bullying while females are more exposed to psychological types of bullying [36]. We do not expect this will have changed the overall pattern of results, though.

Due to the retrospective nature of the study, recall bias may have been present if the twins themselves considered childhood bullying as a major risk factor for adult obesity. The participants were therefore asked what they believed were the causes of their weight gain.

None gave answers which indicated that having been bullied in childhood was considered a determinant of obesity. This question was posed after the OBVQ.

The results may to some degree be confounded by genetic effects, something that could have been further investigated if we could have stratified the sample by zygosity. This was not possible due to power problems, despite the fact that the sample size is big when taking the phenotype into consideration.

Peer and/or teacher reports are believed to provide an objective measure of the number of victims in any class at a given time, but they do not necessarily provide an estimate of the frequency of the bullying behavior. Thus, in order to obtain insights into the experience of children, we have to rely upon the recollections of the victims [36], with the inherent recall problems. It has been found [29, 37] that former victims are accurate in their estimates of the severity of such behavior and their memories were stable over the years suggesting that the accuracy of recall for these events was not affected by time [36].

Selective non-participation could also have flawed our results. However, the 17 pairs not taking part in the study were found to be representative with regard to the inclusion criteria. Furthermore, it may be argued that the direction of the causation could be a concern, since having been bullied as children could be because they were already overweight at that point in time [38]. To exclude this option, we included twin participants only if they reported to have been normal weight as children.

Finally, in this study it was assumed that the discordant twin pairs were raised together, because we have no knowledge of the opposite.

In summary, the results of the present study indicate that childhood bullying may not only be an important and immediate psychosocial problem, but additionally may have important long term consequences in the form of overweight or obesity in adulthood.

\section{Key Points}

Overweight and obesity have increased significantly world-wide over the past decades in both sexes, all age groups, of all ethnicities and at all educational levels. The prevalence has tripled in many countries in the WHO European region since the 1980 's, and the numbers of those affected continue to rise at an alarming rate.

Childhood exposure to bullying has been studied in relation to later psychosocial health and quality of life but it has further been suggested that bullying during childhood may be of importance also for future somatic health and thus also for development of overweight and obesity.

Previous studies have examined bullying among children who were already overweight or obese and related this to different health outcomes.

It has not previously been examined whether childhood bullying could be a risk factor and be related to the subsequent development of adult obesity among initially normal weight children.

The results of the present twin study indicate that childhood bullying may not only be an important and immediate psychosocial problem, but additionally may have important long term consequences in the form of overweight or obesity in adulthood.

This suggests that by preventing bullying in childhood the prevalence of overweight and obesity would decrease, which could be important news regarding public health.

\section{ACKNOWLEDGEMENTS}

The authors gratefully acknowledge support of this study: The European Union Contract No. QLG2-CT-2002-01254 (the GenomEUtwin project). The Else and Mogens Wedell-Wedellborgs Foundation, The director Jacob Madsen \& wife Olga Madsen Foundation, The Danish Health Foundation and Danish Nurses' Organization.

\section{REFERENCES}

[1] Golan, M. (2006) Parents as agents of change in childhood obesity-From research to practice. International Journal of Pediatric Obesity, 1, 66-76. doi:10.1080/17477160600644272

[2] Lissau, I. and Sorensen, T.I. (1993) School difficulties in childhood and risk of overweight and obesity in young adulthood: A ten year prospective population study. International Journal of Obesity and Related Metabolic Disorders, 17, 169-75.

[3] Mamun, A.A., Lawlor, D.A., O'Callaghan, M.J., Bor, W., Williams, G.M. and Najman, J.M. (2007) Does childhood sexual abuse predict young adult's BMI? A birth cohort 
study. Obesity, 15, 2103-2110. doi:10.1038/oby.2007.250

[4] Oliveira, A.M., Oliveira, A.C., Almeida, M.S., Oliveira, N. and Adan, L. (2007) Influence of the family nucleus on obesity in children from northeastern Brazil: A crosssectional study. BMC Public Health, 7, 235. doi:10.1186/1471-2458-7-235

[5] Gunstad, J., Paul, R.H., Spitznagel, M.B., et al. (2006) Exposure to early life trauma is associated with adult obesity. Psychiatry Research, 142, 31-37. doi:10.1016/j.psychres.2005.11.007

[6] McElroy, S.L., Kotwal, R., Malhotra, S., Nelson, E.B., Keck, P.E. and Nemeroff, C.B. (2004) Are mood disorders and obesity related? A review for the mental health professional. Journal of Clinical Psychiatry, 65, 634-651. doi:10.4088/JCP.v65n0507

[7] Vámosi, M.E., Heitmann, B.L., Thinggaard, M., Kyvik, K.O. (2011) Parental care in childhood and obesity in adulthood-A study among twins. Obesity, 19, 14451450. doi: $10.1038 /$ oby. 2011.20

[8] Olweus, D. (1994) Bullying at school. Basic facts and an effective intervention programme. Promote Education, 1, 27-31, 48. doi:10.1177/102538239400100414

[9] Richter, M., Bowles, D., Melzer, W. and Hurrelmann, K. (2007) Bullying, psychosocial health and risk behaviour in adolescence. Gesundheitswesen, 69, 475-482. doi:10.1055/s-2007-985876

[10] Schäfer, M. and Korn, S. (2004) Lonely in the crowd: Recollections of bullying. British Journal of Developmental Psychology, 22, 379-394. doi:10.1348/0261510041552756

[11] Srabstein, J.C., McCarter, R.J., Shao, C. and Huang, Z.J. (2006) Morbidities associated with bullying behaviors in adolescents. School based study of American adolescents. International Journal of Adolescent Medicine and Health, 18, 587-596. doi:10.1515/IJAMH.2006.18.4.587

[12] Duffy, D.L., Mitchell, C.A. and Martin, N.G. (1998) Genetic and environmental risk factors for asthma: A cotwin-control study. American Journal of Respiratory and Critical Care Medicine, 157, 840-845.

[13] Hall, J.G. (2003) Twinning. Lancet, 362, 735-743. doi:10.1016/S0140-6736(03)14237-7

[14] Schousboe, K., Willemsen, G., Kyvik, K.O., et al. (2003) Sex differences in heritability of BMI: A comparative study of results from twin studies in eight countries. Twin Research, 6, 409-421.

[15] Stubbe, J.H., Boomsma, D.I., Vink, J.M., et al. (2006) Genetic influences on exercise participation in 37,051 twin pairs from seven countries. PloS ONE, 1, e22. doi:10.1371/journal.pone.0000022

[16] Kyvik, K.O. (2000) Generalisability and assumptions of twin studies. In: Spector, T.D., Snieder, H. and Mac Fregor, A.J., Eds., Advances in twin and sib-pair analysis. London Greenwich Medical Media Ldt., London, 67-77.

[17] Skytthe, A., Kyvik, K., Holm, N.V., Vaupel, J.W. and Christensen, K. (2002) The Danish twin registry: 127 birth cohorts of twins. Twin Research, 5, 352-357.

[18] Rothman, K.J. and Greenland, S. (1998) Modern epidemiology. 2nd Edition, Lippincott-Raven, Philadelphia, 163-
182.

[19] Cohen, S., Kamarck, T. and Mermelstein, R. (1983) A global measure of perceived stress. Journal of Health and Social Behavior, 24, 385-396. doi:10.2307/2136404

[20] Eriksson, M. and Lindstrom, B. (2006) Antonovsky's sense of coherence scale and the relation with health: A systematic review. Journal of Epidemiology \& Community Health, 60, 376-381. doi:10.1136/jech.2005.041616

[21] Fejer, R., Hartvigsen, J. and Kyvik, K.O. (2006) Sex differences in heritability of neck pain. Twin Research and Human Genetics, 9,198-204. doi:10.1375/twin.9.2.198

[22] Garner, D.M., Olmsted, M.P. and Polivy, J. (1983) Development and validation of a multidimensional eating disorder inventory for anorexia nervosa and bulimia. International Journal of Eating Disorders, 2, 15-34. doi:10.1002/1098-108X(198321)2:2<15::AID-EAT22600 20203>3.0.CO;2-6

[23] Parsons, T.J., Power, C. and Manor, O. (2001) Fetal and early life growth and body mass index from birth to early adulthood in 1958 British cohort: Longitudinal study. BMJ, 323, 1331-1335. doi:10.1136/bmj.323.7325.1331

[24] Sorensen, T.I., Stunkard, A.J., Teasdale, T.W. and Higgins, M.W. (1983) The accuracy of reports of weight: Children's recall of their parents' weights 15 years earlier. International Journal of Obesity, 7, 115-122.

[25] Wee, C.C., Davis, R.B. and Hamel, M.B. (2008) Comparing the SF-12 and SF-36 health status questionnaires in patients with and without obesity. Health and Quality of Life Outcomes, 6, 11. doi:10.1186/1477-7525-6-11

[26] Glew, G.M., Fan, M.Y., Katon, W. and Rivara, F.P. (2008) Bullying and school safety. Journal of Pediatrics, 152, 123-128.

[27] Kristensen, S.M. and Smith, P.K. (2003) The use of coping strategies by Danish children classed as bullies, victims, bully/victims, and not involved, in response to different (hypothetical) types of bullying. Scandinavian Journal of Psychology, 44, 479-488. doi:10.1046/j.1467-9450.2003.00369.x

[28] Kyriakides, L., Kaloyirou, C. And Lindsay, G. (2006) An analysis of the revised Olweus bully/victim questionnaire using the Rasch measurement model. British Journal of Educational Psychology, 76, 781-801. doi:10.1348/000709905X53499

[29] Olweus, D. (1993) Bullying at school; What we know and what we can do. Blackwell Publishers, Oxford.

[30] WHO (1995) WHO physical status: The use and interpretation of anthropometry. WHO Expert Committee. Series No. 854, 368-369.

[31] Wikland, K.A., Luo, Z.C., Niklasson, A. and Karlberg, J. (2002) Swedish population-based longitudinal reference values from birth to 18 years of age for height, weight and head circumference. Acta Paediatrica, 91, 739-754. doi:10.1111/j.1651-2227.2002.tb03322.x

[32] Arseneault, L., Milne, B.J., Taylor, A., et al. (2008) Being bullied as an environmentally mediated contributing factor to children's internalizing problems: A study of twins discordant for victimization. The Archives of Pediatrics \& Adolescent Medicine, 162, 145-150. 
doi:10.1001/archpediatrics.2007.53

[33] Fejer, R. and Hartvigsen, J. (2008) Neck pain and disability due to neck pain: What is the relation? European Spine Journal, 17, 80-88. doi:10.1007/s00586-007-0521-9

[34] Crawley, H.F. and Portides, G. (1995) Self-reported versus measured height, weight and body mass index amongst 16 - 17 years old British teenagers. International Journal of Obesity and Related Metabolic Disorders, 19, 579-584.

[35] Niedhammer, I., Bugel, I., Bonenfant, S., Goldberg, M. and Leclerc, A. (2000) Validity of self-reported weight and height in the French GAZEL cohort. International Journal of Obesity and Related Metabolic Disorders, 24,
1111-1118. doi:10.1038/sj.ijo.0801375

[36] Solberg, M.E., Olweus, D. and Endresen, I.M. (2007) Bullies and victims at school: Are they the same pupils? British Journal of Educational Psychology, 77, 441-464. doi:10.1348/000709906X105689

[37] Rivers, I. (2001) Retrospective reports of school bullying: Stability of recall and its implications for research. British Journal of Developmental Psychology, 19, 129-142. doi:10.1348/026151001166001

[38] Hill, A.B. (1965) The environment and disease: Association or causation? Proceeding of the Royal Society of Medicine, 58, 295-300. 